\title{
Oxidative Stress, Epigenetics, and Cancer Stem Cells in Arsenic Carcinogenesis and Prevention
}

\author{
Lingzhi Li ${ }^{1}$ - Fei Chen ${ }^{1}$
}

Published online: 23 January 2016

(C) Springer International Publishing AG 2016

\begin{abstract}
The carcinogenic role of arsenic has been extensively studied for more than half century. How arsenic causes human cancer, however, remains to be fully elucidated. In this brief review, we focus our attentions on the most recent discoveries by us and others on the capabilities of arsenic in inducing generation of reactive oxygen species (ROS), expression of microRNAs (miRNAs), and the generation of the cancer stem cells. We believe that these new understandings on the mechanisms of arsenic-induced carcinogenesis will shed light on the prevention and treatment of human cancers resulted from environmental or occupational arsenic exposure. Furthermore, these latest findings on arsenicinduced cellular responses will also have an important impact on the investigation of the carcinogenic effects of other environmental or occupational carcinogens or hazards.
\end{abstract}

Keywords Arsenic $\cdot$ Oxidative stress $\cdot$ Epigenetics $\cdot$ Cancer stem cells

\section{Arsenic in Environmental and Occupational Settings}

Arsenic is one of the most abundant components of the Earth's crust and can be commonly found as compounds in rocks, soil, ground waters, air, food, and in plants and animals.

This article is part of the Topical Collection on Free Radicals Medicine

Fei Chen

fchen@wayne.edu

1 Department of Pharmaceutical Sciences, Eugene Applebaum College of Pharmacy and Health Sciences, Wayne State University, 259 Mack Avenue, Detroit, MI 48201, USA
Naturally, arsenic is rarely found as a pure metalloid, but is often as a key element in inorganic and organic compounds. Inorganic arsenic, mostly in combination with oxygen, chlorine, sulfur, and other metal elements, such as $\mathrm{As}_{2} \mathrm{O}_{3}, \mathrm{AsCl}_{3}$, $\mathrm{As}_{2} \mathrm{~S}_{3}, \mathrm{FeAsS}$ (arsenopyrite), and $\mathrm{As}_{4} \mathrm{~S}_{4}$ (realgar), is widely distributed in the environment [1]. It is released into the air by volcanoes, the weathering of arsenic-containing minerals and ores and by commercial or industrial activities. Organic arsenic contains carbon and hydrogen, such as arsenobataine, arsenocholine, tetramethylarsonium salts, arsenosugars, and arsenic-containing lipids that can be found in some marine organisms and terrestrial species [2]. Several organic arsenic compounds were developed as chemical warfare agents during World War I, including lewisite and adamsite. In general, the inorganic arsenic poses the most health concerns in human being, whereas majority of the organic arsenic compounds are less toxic.

Drinking water contamination of arsenic is the main source of environmental arsenic exposure to human being. This arsenic contamination in drinking water is largely resulted from natural deposition of arsenic-bearing minerals in the underground rocks or sediments. The arsenic minerals can be released to the water through either oxidation or the reduction of $\mathrm{Fe} / \mathrm{As}$ oxyhydroxides [3]. It is believed that some agriculture activities causing excessive withdrawal and lowering of the water table facilitate oxidation of arsenic-containing pyrite in the sediment [1]. Recharge of the water table by rainfall causes leaches out of arsenic from the sediment into the aquifer. Under some geological and microenvironmental circumstances, such as in wet and flat regions and aerobic alkaline conditions in closed basins in arid and semiarid region, arsenic forms co-precipitates with ferric oxyhydroxides, which enforces the reducing conditions of the groundwater. This reducing status is further enhanced by microbial-based oxidation of organic carbon followed by depletion of the dissolved oxygen in the groundwater [4]. 
A number of anthropogenic activities are at risk of increasing occupational and environmental arsenic exposures. These activities include mining, smelting of non-ferrous metals, energy production from fossil fuel, manufacture of semiconductors, agriculture application of arsenic-based insecticides and herbicides, and processing of wood preservatives, alloying agents, glass, pigments, textiles, papers, metal adhesives, ammunition, etc. Mining dumps, or tailings that usually contain high amount of arsenic and other toxic metals, can contaminate not only the surrounding topsoil but the groundwater also [5]. In USA alone, it is estimated that there are several billion tons of tailings stored in some historic and active mining sites. These tailings impose considerable threat to the environment and public health. The most recent accidental release of more than 11 million liters of tailings in the major waterways due to human error is perhaps the best example of such a threat [6].

\section{Arsenic and Human Cancers}

Several large-scale epidemiological or case-control studies had provided unequivocal evidence suggesting that arsenic is a human carcinogen. In 1987, The International Agency for Research on Cancer (IARC) had classified inorganic arsenic and its derivatives, including those compounded with sulfur, chloride, and among others, as group I carcinogens. Excessive exposure to arsenic is reported to be involved in the development processes of various types of cancer (e.g., lung, skin, bladder) [7]. Currently, there is an estimation that about 160 million people exposed to elevated level of arsenic in drinking water worldwide [8]. Thus, it is urgently needed to understand mechanisms of arsenic-induced tumorigenesis, which may be helpful for prevention of the arsenic-related malignancy.

Although arsenic has been considered as a poorer mutagen, increasing evidence suggests that arsenic is highly capable of promoting epigenetic alterations, including DNA methylation $[9,10]$, histone methylation [11, 12], histone phosphorylation/ acetylation [13, 14], and microRNA regulation [14, 15], through some signaling mediators, e.g., $\operatorname{ROS}[16,17]$, Akt $[15,18,19]$, and FilaminA [20] that are required for arsenicinduced cell transformation. However, the mechanisms of how arsenic elicits those effects remain elusive.

\section{Arsenic Induces Excessive Generation of Reactive Oxygen Species}

There are two types of inorganic arsenic presented naturally, the pentavalent arsenate $\left(\mathrm{As}^{5+}\right)$, and its reduced form, the trivalent arsenite $\left(\mathrm{As}^{3+}\right)$ [21]. In general, the trivalent arsenic $\left(\mathrm{As}^{3+}\right)$ is able to function as the main inducer of ROS generation within cells [22]. There are several types of ROS generated during arsenic metabolism, such as peroxyl radicals (ROO•), superoxide anion radical $\left(\mathrm{O}^{-}{ }^{-}\right)$, hydroxyl radical $(\bullet \mathrm{OH})$, hydrogen peroxide $\left(\mathrm{H}_{2} \mathrm{O}_{2}\right)$, and other organic arsenic intermediates [23]. As reported, cells uptake arsenic through different membrane transporters, for example, the aquaglyceroporins are the transporters in human and rat cells [24] and hexose permeases in Saccharomyces cerevisiae [25]. The penetration of arsenate into the cells could be achieved through some phosphate transporters [26]. When inside the cells, arsenate will be metabolized to its reduced form, arsenite, through glutathione, and finally turns to its organic form, monomethylarsonic acid (MMA) or dimethylarsinic acid (DMA) [27].

Many living cells are able to convert arsenite to arsenate through oxidation, which generates two electrons important for the formation of hydrogen peroxide $\left(\mathrm{H}_{2} \mathrm{O}_{2}\right)$ [28]. By Fenton reaction, the $\mathrm{H}_{2} \mathrm{O}_{2}$ produces hydroxyl radical, a very active oxygen radical contributing to a wide range of macromolecule oxidation [29]. In addition to the ROS generation from arsenic metabolism, arsenic can also heighten ROS generation by activating the membrane-bound NADPH oxidase complex, which is responsible for the release of superoxide anion radical $\left(\mathrm{O}^{\circ}{ }^{-}\right)$[30]. At last, it had been reported that arsenic perturbs mitochondrial membrane integrity and potential leading to the release of ROS from mitochondria to cytoplasm [27, 31].

Mammalian cells equipped with several different antioxidant systems to scavenge or neutralize lower to moderate levels of ROS to prevent oxidative stress and tissue injury. However, excessive generation of ROS will overwhelm the cellular antioxidant capability, leading to oxidative damages on DNA, lipid, protein, as well as the activation of some cell proliferative or stress signaling pathways, such as TNF $\alpha /$ NF-kB [32, 33], JNK/AP-1 [34, 35], c-myc [36, 37], MAPK $[16,38]$, and Wnt/ beta-catenin $[39,40]$. In terms of DNA damage caused by ROS, there are reports demonstrating that the ROS-mediated genomic mutation is very likely an earlier initiation step in the cancer development [41]. Furthermore, excess ROS can also cause damage to lipids, further leading to DNA damage and consequently impair the activity of DNA repair enzymes $[42,43]$. Several lines of evidence indicate that the protein damage caused by excessive ROS can influence the DNA error-prone repair system and therefore leading to cancer development [44]. The DNA repair systems comprise a number of enzymes, while the unnecessary modifications, such as oxidations, can hamper their activities and eventually impair the DNA damage repair pathways. In our most recent studies, we uncovered an entirely unexplored new mechanism linking arsenic exposure to a compromised DNA repair function. In human bronchial epithelial cells or lung cancer cell line A549 cells, arsenic is potent in inducing mdig expression [45]. By exploring potential interaction partners of the mdig protein, we conducted proteomic analysis of the 
immunocomplexes from mdig immunoprecipitation and revealed direct interaction of mdig with XRCC5, XRCC6, and DNAPK, the non-homologous end-joining (NHEJ) repair complex. Functional analysis further showed that this interaction weakens DNA double-strand repair function of the NHEJ complex [46].

\section{Epigenetics in Arsenic-Induced Carcinogenesis}

Epigenetics refers to the modifications on genomes without changes in DNA sequences, such as DNA methylation, histone tail modification, as well as non-coding RNA. Generally speaking, DNA methylation occurred at the $\mathrm{CpG}$ island of the promoter region that is inhibitory for gene expression [47]. For decades, perturbation in DNA methylation pattern on the genome has been linked to a myriad of human diseases, such as neurodegenerative diseases, psychological disorders, and cancers [48]. It had been well known that DNA methylation inhibits expression of certain tumor suppressors, thus promotes malignant transformation of the cells. The histone proteins, especially. in the histone tail region of the nucleosomes, undergo multiple post-transcriptional modifications, including methylation, acetylation, phosphorylation, sumoylation, unbiquitylation [49], and biotinylation [50]. Some modifications facilitate formation of the permissive chromatin structures for transcription factor binding and gene expression, whereas other modifications might result to silencing of the genome due to the non-permissive heterochromatin configuration. The polycomb repressive complex 2 (PRC2) is known to catalyze tri-methylation of the lysine 27 on histone $\mathrm{H} 3$ (H3K27me3), leading to gene silencing. This methylation is achieved by the key catalytic subunit, enhancer of zeste homologue 2 (EZH2), a methytransferase. Interestingly, overexpression of EZH2 had been observed in a variety of human cancers $[51,52]$, suggesting its pivotal role in cancer development. The enzymatic activity of EZH2 is subjected to the multi-layer regulation, one of which is its phosphorylation on serine 21 (S21) [53]. In human bronchial epithelial cells, we found that arsenic is able to induce S21 phosphorylation through the JNK-STAT3-Akt signaling cascade [18]. Applying the cells with chemical inhibitors or small-interfering RNAs (siRNAs) targeting JNK, STAT3, or Akt prevented S21 phosphorylation of EZH2 in response to arsenic. Additional tests unraveled that this arsenic-induced EZH2 phosphorylation is partially dependent on the generation of ROS, as the fact that antioxidant N-acetyl-L-cysteine (NAC) could prevent, whereas $\mathrm{H}_{2} \mathrm{O}_{2}$ promotes EZH2 phosphorylation in the cells treated with arsenic [16]. The fate of the S21-phosphorylated EZH2 is still a mystery. By examining intracellular distribution of the S21-phosphorylated and non-phosphorylated EZH2 proteins through immunofluorescent staining, we had noted cytoplasmic localization of the
S21-phosphorylated EZH2 protein [16, 18]. Accordingly, we speculated that this phosphorylated EZH2 induced by arsenic may act on some non-histone proteins.

The non-coding RNAs had long been viewed as "junk." Nonetheless, emerging evidence suggested the important regulatory functions of the non-coding RNAs. There are several members of the non-coding RNA family, such as t-RNA (transfer-RNA), rRNA (ribosomal-RNA), snoRNA (small nucleolar RNA), siRNA (small-interfering RNA), snRNA (small nuclear RNA), exRNA (extracellular RNA), piRNA (piwiinteracting RNA), lincRNA (large intergenic non-coding RNA), T-UCR (transcribed ultraconserved regions), and miRNA (microRNA).

MicroRNAs (miRNAs) belong to the class of short noncoding RNAs with the length of 19-25 nucleotides. They mainly function as the silencers of certain mRNAs. In mammals, the "seed region," a sequence of two to eight nucleotidelong in the miRNA 5'-end region, binds to the 3'-UTR region of mRNAs [54]. Depending on the degree of their binding, miRNAs can either mediate translational suppression or target mRNAs for degradation. The miRNA genes are first transcribed into primary miRNA (pri-miRNA) with the help of RNA polymerase II. The pri-miRNA is spliced by DroshaDGCR8 to precursor miRNA (pre-miRNA) that transported from nucleus to cytoplasm by exportin 5 . In cytoplasm, premiRNA undergoes further splice by Dicer-TRBP/PACT to generate mature miRNA. After release of the passage strand, the single-strand mature miRNA is incorporated into RNA-induced silencing complex (RISC) that guides miRNA to its complementary mRNA. Depending on complementarity between miRNA and mRNA, the miRNA can either suppress translation of mRNA or induce degradation of mRNA.

During the process of carcinogenesis or tumorigenesis, some miRNAs serve as the tumor suppressors by targeting oncogenes, for example, mir-101 decreases the expression of EZH2 [55], while others may function as oncomirs that promote cancer development by targeting tumor suppressors, such as mir-21 that downregulates PTEN and PDCD4 [56]. Emerging evidence also indicates that arsenic-induced carcinogenesis is profoundly associated with miRNA regulations $[57,58]$. In our previous studies, we found that arsenic is able to induce expression of miR-190, a miRNA that can silence PHLPP, a negative regulator of Akt [15]. Additional studies also suggested that arsenic can heighten expression of miR21, a well-established oncomir [18]. Biochemical analysis demonstrated that the induction of miR-21 by arsenic is very likely through the JNK-dependent STAT3 activation. Increased expression of miR-21 can suppress PTEN, another negative regulator of Akt. In our most recent experiments in testing the hypothesis that long-term arsenic exposure fosters formation of the cancer stem cells, we found that consecutive treatment of the cells with lower concentration of arsenic 
enhances expression of miR214, which may target some chromatin remodeling proteins ( $\mathrm{Li}$ et al., unpublished).

\section{Cancer Cell Stemness in Arsenic-Induced Carcinogenesis}

Cancer stem cells (CSCs) are a small population of tumor cells that have the ability of self-renewal and differentiation [59]. A well-established CSC model of tumorigenesis indicates that $\mathrm{CSCs}$ are the key for tumor initiation, progression, therapeutic resistance, and metastasis $[60,61]$. Despite extensively explored, there are still challenges in identifying unique surface markers, genetic characteristics, epigenetic features, and the cellular ancestors of the CSCs.

Mounting evidence implies that prolonged arsenic exposure not only promotes malignant transformation of the noncancerous cells but also confers the cancer cell stem-like properties [62-64]. In our recent study, we elucidated that sublethal arsenic exposure triggers transformation of the bronchial epithelial cells, and some of these transformed cells exhibited features of the CSCs, e.g., increased expression of the stemness genes, including Sox2, KLF4, Oct4, Nanog, and myc [63]. Although we failed to detect those reported CSC surface markers, such as CD133, CD24, CD44, CD166, CD326, and CD184, we did find that the CSCs induced by arsenic is $\mathrm{CD}^{-}{ }^{-}$[63]. From our previous studies, we unexpectedly observed that the transformed cells induced by arsenic had a reduced capability of ROS generation [65]. In agreement with this notion, the CSCs induced by arsenic also showed a diminished generation of ROS in response to an additional arsenic treatment. In the non-transformed cells, we had consistently detected ROS generation and the activation of several cell proliferative cellular pathways following arsenic treatment. Furthermore, as proposed originally, arsenic-induced cancer cell stem-like properties is highly associated with Ras and Akt expression [58]. It is unclear why the cells lost their ability of ROS generation when converted to CSCs. Gene profiling revealed that the genes important for mitochondrial oxidative phosphorylation (OXPHOS) were repressed substantially in the CSCs, whereas genes involved in the glycolysis were upregulated [66]. Since majority of cellular ROS are generated from OXPHOS, it is very likely that compromising OXPHOS will result in the lower capability of the cells to produce ROS. From the evolutional perspectives of the CSCs, diminished ROS generation favors the stemness of the CSCs. It has been generally accepted that ROS can not only induce apoptosis and differentiation of the CSCs but also inactivate the activities of the CSC transcription factors essential for the self-renewal of the CSCs. Thus, reduced ROS production might be an important measure for the maintenance of the CSCs. This hypothesis was supported by experiments in other cancer models, for example, ROS inhibits selfrenewal of ovarian cancer CSCs [67] and kills the drugresistant CSCs [68].

\section{Perspectives}

The role of arsenic in cancer development has not been fully understood and because of the complex signaling pathways mediated by arsenic, some debates remain. From the cellular and animal cancer models, results from our laboratory and others clearly demonstrated that the carcinogenic effects of
Fig. 1 Underlying mechanisms of arsenic induced malignant transformation. Arsenic exerts its carcinogenic property most likely through impacts on epigenetics, genetics, immune surveillance, and DNA damage repair

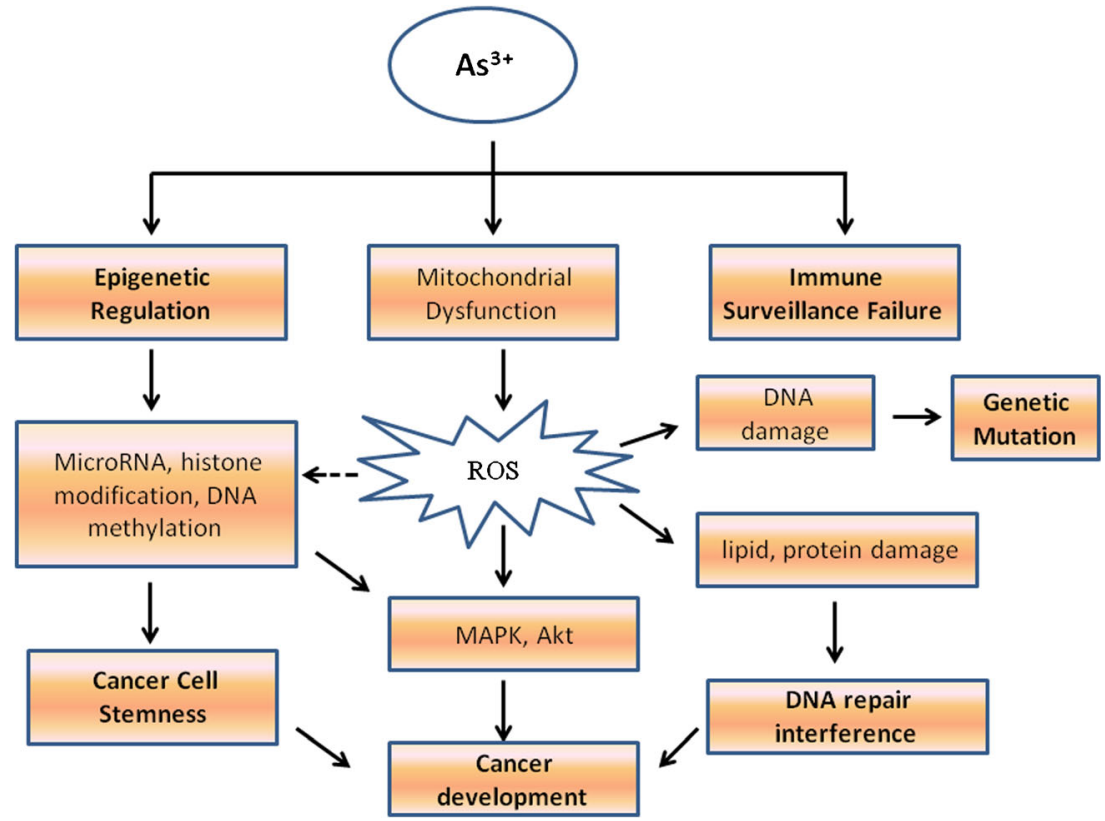


arsenic may be achieved through influences on epigenetics, genetics, immune surveillance, DNA repair, and intracellular kinases and/or transcription factor signaling pathways [69] (Fig. 1). These multiple effects of arsenic may finally shift the cellular metabolic programs that converged on the malignant transformation and generation of the CSCs. Since the emerging evidence suggests the central role of CSCs in cancer initiation, progression, chemoresistance, metastasis, and tumor recurrence [70-72], targeting CSCs should be a new strategy for cancer therapy. It has been known that current chemodrugs have limited capability to kill the CSCs in any given tumors. Thus, understanding the molecular mechanisms of arsenic-induced cancer, such as altered dynamics of ROS generation [73] and miRNA expression [74], will certainly shed new light for future cancer therapy.

\section{Compliance with Ethical Standards}

Conflict of Interest On behalf of all authors, the corresponding author states that there is no conflict of interest.

Human and Animal Rights and Informed Consent This article does not contain any studies with human and or animal subjects performed by any of the authors.

\section{References}

1. Garelick H, Jones H, Dybowska A, Valsami-Jones E. Arsenic pollution sources. Rev Environ Contam Toxicol. 2008;197:17-60.

2. Amaral CD, Nobrega JA, Nogueira AR. Sample preparation for arsenic speciation in terrestrial plants - a review. Talanta. 2013;115:291-9.

3. Nickson R, McArthur J, Burgess W, Ahmed KM, Ravenscroft P, Rahman M. Arsenic poisoning of Bangladesh groundwater. Nature. 1998;395(6700):338.

4. Rodriguez-Lado L, Sun G, Berg M, et al. Groundwater arsenic contamination throughout China. Science. 2013;341(6148):866-8.

5. Menka N, Root R, Chorover J. Bioaccessibility, release kinetics, and molecular speciation of arsenic and lead in geo-dusts from the Iron King Mine Federal Superfund site in Humboldt. Ariz Rev Environ Health. 2014;29(1-2):23-7.

6. Tenenbaum DJ. Oil sands development: a health risk worth taking? Environ Health Perspect. 2009;117(4):A150-6.

7. Tchounwou PB, Patlolla AK, Centeno JA. Carcinogenic and systemic health effects associated with arsenic exposure - a critical review. Toxicol Pathol. 2003;31(6):575-88.

8. Martinez VD, Vucic EA, Lam S, Lam WL. Arsenic and lung cancer in never-smokers: lessons from Chile. Am J Respir Crit Care Med. 2012;185(10):1131-2.

9. Han ZJ, Song G, Cui Y, Xia HF, Ma X. Oxidative stress is implicated in arsenic-induced neural tube defects in chick embryos. Int $\mathrm{J}$ Dev Neurosci. 2011;29(7):673-80.

10. Bustaffa E, Stoccoro A, Bianchi F, Migliore L. Genotoxic and epigenetic mechanisms in arsenic carcinogenicity. Arch Toxicol. 2014;88(5):1043-67.

11. Zhou X, Sun H, Ellen TP, Chen H, Costa M. Arsenite alters global histone H3 methylation. Carcinogenesis. 2008;29(9):1831-6.
12. Brocato J, Costa M. 10th NTES conference: nickel and arsenic compounds alter the epigenome of peripheral blood mononuclear cells. J Trace Elem Med Biol. 2015;31:209-13.

13. Li J, Gorospe M, Barnes J, Liu Y. Tumor promoter arsenite stimulates histone $\mathrm{H} 3$ phosphoacetylation of proto-oncogenes c-fos and c-jun chromatin in human diploid fibroblasts. J Biol Chem. 2003;278(15):13183-91.

14. Ren X, McHale CM, Skibola CF, Smith AH, Smith MT, Zhang L. An emerging role for epigenetic dysregulation in arsenic toxicity and carcinogenesis. Environ Health Perspect. 2011;119(1):11-9.

15. Beezhold K, Liu J, Kan H, et al. miR-190-mediated downregulation of PHLPP contributes to arsenic-induced Akt activation and carcinogenesis. Toxicol Sci. 2011;123(2):411-20.

16. Li L, Qiu P, Chen B, et al. Reactive oxygen species contribute to arsenic-induced EZH2 phosphorylation in human bronchial epithelial cells and lung cancer cells. Toxicol Appl Pharmacol. 2014;276(3):165-70.

17. Shi H, Shi X, Liu KJ. Oxidative mechanism of arsenic toxicity and carcinogenesis. Mol Cell Biochem. 2004;255(1-2):67-78.

18. Chen B, Liu J, Chang Q, Beezhold K, Lu Y, Chen F. JNK and STAT3 signaling pathways converge on Akt-mediated phosphorylation of EZH2 in bronchial epithelial cells induced by arsenic. Cell Cycle. 2013;12(1):112-21.

19. Stueckle TA, Lu Y, Davis ME, et al. Chronic occupational exposure to arsenic induces carcinogenic gene signaling networks and neoplastic transformation in human lung epithelial cells. Toxicol Appl Pharmacol. 2012;261(2):204-16.

20. Li L, Lu Y, Stemmer PM, Chen F. Filamin a phosphorylation by Akt promotes cell migration in response to arsenic. Oncotarget. 2015;6(14):12009-19.

21. Vahter M. Mechanisms of arsenic biotransformation. Toxicology. 2002;181-182:211-7.

22. Ellinsworth DC. Arsenic, reactive oxygen, and endothelial dysfunction. J Pharmacol Exp Ther. 2015;353(3):458-64.

23. Flora SJ, Saxena G, Gautam P, Kaur P, Gill KD. Response of leadinduced oxidative stress and alterations in biogenic amines in different rat brain regions to combined administration of DMSA and MiADMSA. Chem Biol Interact. 2007;170(3):209-20.

24. Liu Z, Carbrey JM, Agre P, Rosen BP. Arsenic trioxide uptake by human and rat aquaglyceroporins. Biochem Biophys Res Commun. 2004;316(4):1178-85.

25. Liu Z, Boles E, Rosen BP. Arsenic trioxide uptake by hexose permeases in Saccharomyces cerevisiae. J Biol Chem. 2004;279(17): 17312-8.

26. Calatayud M, Gimeno J, Velez D, Devesa V, Montoro R. Characterization of the intestinal absorption of arsenate, monomethylarsonic acid, and dimethylarsinic acid using the Caco-2 cell line. Chem Res Toxicol. 2010;23(3):547-56.

27. Jomova K, Jenisova Z, Feszterova M, et al. Arsenic: toxicity, oxidative stress and human disease. J Appl Toxicol. 2011;31(2): 95-107.

28. Valko M, Morris H, Cronin MT. Metals, toxicity and oxidative stress. Curr Med Chem. 2005;12(10):1161-208.

29. Jomova K, Valko M. Advances in metal-induced oxidative stress and human disease. Toxicology. 2011;283(2-3):65-87.

30. Chou WC, Jie C, Kenedy AA, Jones RJ, Trush MA, Dang CV. Role of NADPH oxidase in arsenic-induced reactive oxygen species formation and cytotoxicity in myeloid leukemia cells. Proc Natl Acad Sci U S A. 2004;101(13):4578-83.

31. Zheng CY, Lam SK, Li YY, Ho JC. Arsenic trioxide-induced cytotoxicity in small cell lung cancer via altered redox homeostasis and mitochondrial integrity. Int J Oncol. 2015;46(3):1067-78.

32. Chen F, Shi X. Intracellular signal transduction of cells in response to carcinogenic metals. Crit Rev Oncol Hematol. 2002;42(1): $105-21$. 
33. Roebuck KA. Oxidant stress regulation of IL-8 and ICAM-1 gene expression: differential activation and binding of the transcription factors AP-1 and NF-kappaB (Review). Int J Mol Med. 1999;4(3): 223-30.

34. Das DK, Maulik N. Preconditioning potentiates redox signaling and converts death signal into survival signal. Arch Biochem Biophys. 2003;420(2):305-11.

35. Vulin AI, Stanley FM. Oxidative stress activates the plasminogen activator inhibitor type 1 (PAI-1) promoter through an AP-1 response element and cooperates with insulin for additive effects on PAI-1 transcription. J Biol Chem. 2004;279(24):25172-8.

36. K CS, Carcamo JM, Golde DW. Antioxidants prevent oxidative DNA damage and cellular transformation elicited by the overexpression of c-MYC. Mutat Res. 2006;593(1-2):64-79.

37. Maya-Mendoza A, Ostrakova J, Kosar M, et al. Myc and Ras oncogenes engage different energy metabolism programs and evoke distinct patterns of oxidative and DNA replication stress. Mol Oncol. 2015;9(3):601-16.

38. Liu S, Wang F, Yan L, et al. Oxidative stress and MAPK involved into ATF2 expression in immortalized human urothelial cells treated by arsenic. Arch Toxicol. 2013;87(6):981-9.

39. Wang X, Mandal AK, Saito H, et al. Arsenic and chromium in drinking water promote tumorigenesis in a mouse colitisassociated colorectal cancer model and the potential mechanism is ROS-mediated Wnt/beta-catenin signaling pathway. Toxicol Appl Pharmacol. 2012;262(1):11-21.

40. Yoshida GJ, Saya H. Inversed relationship between CD44 variant and c-Myc due to oxidative stress-induced canonical Wnt activation. Biochem Biophys Res Commun. 2014;443(2):622-7.

41. Ruiz-Ramos R, Lopez-Carrillo L, Rios-Perez AD, De Vizcaya-Ruiz A, Cebrian ME. Sodium arsenite induces ROS generation, DNA oxidative damage, HO-1 and c-Myc proteins, NF-kappaB activation and cell proliferation in human breast cancer MCF-7 cells. Mutat Res. 2009;674(1-2):109-15.

42. Wells PG, McCallum GP, Chen CS, et al. Oxidative stress in developmental origins of disease: teratogenesis, neurodevelopmental deficits, and cancer. Toxicol Sci. 2009;108(1):4-18.

43. Dizdaroglu M, Jaruga P. Mechanisms of free radical-induced damage to DNA. Free Radic Res. 2012;46(4):382-419.

44. Emanuele E, Spencer JM, Braun M. From DNA repair to proteome protection: new molecular insights for preventing non-melanoma skin cancers and skin aging. J Drugs Dermatol. 2014;13(3):274-81.

45. Sun J, Yu M, Lu Y, et al. Carcinogenic metalloid arsenic induces expression of mdig oncogene through JNK and STAT3 activation. Cancer Lett. 2014;346(2):257-63.

46. Wang W, Lu Y, Stemmer PM, et al. The proteomic investigation reveals interaction of mdig protein with the machinery of DNA double-strand break repair. Oncotarget, 2015.

47. Arita A, Costa M. Epigenetics in metal carcinogenesis: nickel, arsenic, chromium and cadmium. Metallomics. 2009;1(3):222-8.

48. Rodenhiser D, Mann M. Epigenetics and human disease: translating basic biology into clinical applications. CMAJ. 2006;174(3): 341-8.

49. Zhang B, Dong Q, Su H, Birchler JA, Han F. Histone phosphorylation: its role during cell cycle and centromere identity in plants. Cytogenet Genome Res. 2014;143(1-3):144-9.

50. Xu YM, Du JY, Lau AT. Posttranslational modifications of human histone H3: an update. Proteomics. 2014;14(17-18):2047-60.

51. Hock H. A complex Polycomb issue: the two faces of EZH2 in cancer. Genes Dev. 2012;26(8):751-5.

52. Alajez NM, Shi W, Hui AB, et al. Enhancer of Zeste homolog 2 $(\mathrm{EZH} 2)$ is overexpressed in recurrent nasopharyngeal carcinoma and is regulated by miR-26a, miR-101, and miR-98. Cell Death Dis. 2010;1:e85.

53. Bredfeldt TG, Greathouse KL, Safe SH, Hung MC, Bedford MT, Walker CL. Xenoestrogen-induced regulation of EZH2 and histone methylation via estrogen receptor signaling to PI3K/AKT. Mol Endocrinol. 2010;24(5):993-1006.

54. Lewis BP, Burge CB, Bartel DP. Conserved seed pairing, often flanked by adenosines, indicates that thousands of human genes are microRNA targets. Cell. 2005;120(1):15-20.

55. Lin C, Huang F, Li QZ, Zhang YJ. miR-101 suppresses tumor proliferation and migration, and induces apoptosis by targeting EZH2 in esophageal cancer cells. Int J Clin Exp Pathol. 2014;7(10):6543-50.

56. Sun Z, Li S, Kaufmann AM, Albers AE. miR-21 increases the programmed cell death 4 gene-regulated cell proliferation in head and neck squamous carcinoma cell lines. Oncol Rep. 2014;32(5): 2283-9.

57. Michailidi C, Hayashi M, Datta S, et al. Involvement of epigenetics and EMT-related miRNA in arsenic-induced neoplastic transformation and their potential clinical use. Cancer Prev Res (Phila). 2015;8(3):208-21.

58. Ngalame NN, Tokar EJ, Person RJ, Xu Y, Waalkes MP. Aberrant microRNA expression likely controls RAS oncogene activation during malignant transformation of human prostate epithelial and stem cells by arsenic. Toxicol Sci. 2014;138(2):268-77.

59. Bjerkvig R, Tysnes BB, Aboody KS, Najbauer J, Terzis AJ. Opinion: the origin of the cancer stem cell: current controversies and new insights. Nat Rev Cancer. 2005;5(11):899-904.

60. Jiang R, Li Y, Zhang A, et al. The acquisition of cancer stem celllike properties and neoplastic transformation of human keratinocytes induced by arsenite involves epigenetic silencing of let-7c via Ras/NF-kappaB. Toxicol Lett. 2014;227(2):91-8.

61. Chen C, Zimmermann M, Tinhofer I, Kaufmann AM, Albers AE. Epithelial-to-mesenchymal transition and cancer stem(-like) cells in head and neck squamous cell carcinoma. Cancer Lett. 2013;338(1):47-56.

62. Jiang R, Li Y, Xu Y, et al. EMT and CSC-like properties mediated by the IKKbeta/IkappaBalpha/RelA signal pathway via the transcriptional regulator, Snail, are involved in the arsenite-induced neoplastic transformation of human keratinocytes. Arch Toxicol. 2013;87(6):991-1000.

63. Chang Q, Chen B, Thakur C, Lu Y, Chen F. Arsenic-induced sublethal stress reprograms human bronchial epithelial cells to CD61 cancer stem cells. Oncotarget. 2014;5(5):1290-303.

64. Ngalame NN, Tokar EJ, Person RJ, Waalkes MP. Silencing KRAS overexpression in arsenic-transformed prostate epithelial and stem cells partially mitigates malignant phenotype. Toxicol Sci. 2014;142(2):489-96.

65. Chang Q, Pan J, Wang X, Zhang Z, Chen F, Shi X. Reduced reactive oxygen species-generating capacity contributes to the enhanced cell growth of arsenic-transformed epithelial cells. Cancer Res. 2010;70(12):5127-35.

66. Pasto A, Bellio C, Pilotto G, et al. Cancer stem cells from epithelial ovarian cancer patients privilege oxidative phosphorylation, and resist glucose deprivation. Oncotarget. 2014;5(12):4305-19.

67. Seino M, Okada M, Shibuya K, et al. Differential contribution of ROS to resveratrol-induced cell death and loss of selfrenewal capacity of ovarian cancer stem cells. Anticancer Res. 2015;35(1):85-96.

68. Raha D, Wilson TR, Peng J, et al. The cancer stem cell marker aldehyde dehydrogenase is required to maintain a drug-tolerant tumor cell subpopulation. Cancer Res. 2014;74(13):3579-90.

69. Huang C, Ke Q, Costa M, Shi X. Molecular mechanisms of arsenic carcinogenesis. Mol Cell Biochem. 2004;255(1-2):57-66.

70. Anderson EC, Hessman C, Levin TG, Monroe MM, Wong $\mathrm{MH}$. The role of colorectal cancer stem cells in metastatic disease and therapeutic response. Cancers (Basel). 2011;3(1): 319-39. 
71. Ahmed N, Abubaker K, Findlay J, Quinn M. Epithelial mesenchymal transition and cancer stem cell-like phenotypes facilitate chemoresistance in recurrent ovarian cancer. Curr Cancer Drug Targets. 2010;10(3):268-78.

72. Yoon SK. The biology of cancer stem cells and its clinical implication in hepatocellular carcinoma. Gut Liver. 2012;6(1):29-40.
73. Bao B, Azmi AS, Li Y, et al. Targeting CSCs in tumor microenvironment: the potential role of ROS-associated miRNAs in tumor aggressiveness. Curr Stem Cell Res Ther. 2014;9(1):22-35.

74. Marsit CJ, Eddy K, Kelsey KT. MicroRNA responses to cellular stress. Cancer Res. 2006;66(22):10843-8. 